\title{
Malignant McKittrick-Wheelock syndrome as a cause of acute kidney injury and hypokalemia: Report of a case and review of literature
}

\author{
Sarthak Malik ${ }^{1}$, Bipadabhanjan Mallick ${ }^{1}$, Kunaal Makkar ${ }^{2}$, Vivek Kumar $^{3}$, Vishal Sharma ${ }^{1, *}$, \\ Surinder Singh Rana ${ }^{1}$
}

${ }^{1}$ Department of Gastroenterology, Postgraduate Institute of Medical Education and Research, Chandigarh, India;

${ }^{2}$ Department of Internal Medicine, Postgraduate Institute of Medical Education and Research, Chandigarh, India;

${ }^{3}$ Department of Nephrology, Postgraduate Institute of Medical Education and Research, Chandigarh, India.

\begin{abstract}
Summary Colonic polyps are usually asymptomatic, and are commonly detected during screening colonoscopy. Severe hypokalemia secondary to secretory diarrhea is a rare presentation of rectal polyps. We present a 70 years old female with hypokalemia and acute kidney injury secondary to secretory diarhea due to moderately differentiated adenocarcinoma of rectum, all of which is syndromically sometimes referred to as McKittrick and Wheelock syndrome. The case is presented because McKittrick-Wheelock syndrome is still more uncommon with malignancy. The syndrome may be associated with other features of hypersecretory diarrhea. Though very rare, clinical suspicion would often lead to diagnosis and appropriate management. We also review the previously published reports of this entity.
\end{abstract}

Keywords: Diarrhea, rectal adenoma, colorectal cancer, hypokalemia

\section{Introduction}

Colonic polyps are usually asymptomatic or lead to nonspecific gastrointestinal complaints. They are mostly diagnosed during screening programmes for prevention of colon cancer. McKittrick and Wheelock syndrome is a rare disorder characterised by a rectal villous adenoma leading to chronic secretory diarrhea which in turn leads to severe dehydration, hypokalemia, hyponatremia and acute kidney injury (1). Occasional reports also describe the presence of underlying malignancy or other histologic entities as a cause of this syndrome. We present a 70 years old female who was admitted with hypokalemia and acute kidney injury, and finally diagnosed to have rectal malignancy.

\section{Case Report}

Released online in J-STAGE as advance publication May 30, 2016.

*Address correspondence to:

Dr. Vishal Sharma, Department of Gastroenterology, Postgraduate Institute of Medical Education and Research, Chandigarh, India.

E-mail: docvishalsharma@gmail.com
A 70 years old female presented to the emergency clinic with generalized weakness and reduced urine output for three days. She also complained of diarrhea for 7 months. The patient described frequency of diarrhea to be five to eight episodes per day, large volume, non-bloody, not improving with fasting and often led to nocturnal awakenings. She also gave a history of tenesmus and crampy lower abdominal pain. She received multiple courses of antibiotics from local practitioners with no relief in diarrhea. She denied any nausea or vomiting. Her symptoms worsened over last 1 week prior to presentation. On examination, she had signs of volume depletion; her pulse rate was 106/min and regular, with dry mucous membranes and blood pressure was 96/60 $\mathrm{mm}$ of $\mathrm{Hg}$ at presentation. Laboratory tests showed serum creatinine as 2.6 (normal: $0.5-1.2$ ) with blood urea being $70 \mathrm{mg} / \mathrm{dL}$. Serum potassium was $2.4 \mathrm{mmol} /$ L (normal: $3.6-5 \mathrm{mmol} / \mathrm{L}$ ), sodium $142 \mathrm{mmol} / \mathrm{L}$ (normal: 135-143 mmol/L), phosphate $1.4 \mathrm{mg} / \mathrm{dL}$ (normal: 2.4 $4.1 \mathrm{mg} / \mathrm{dL}$ ) and magnesium levels were $1.53 \mathrm{mg} / \mathrm{dL}$ (normal: 1.7-2.2 mg/dL). Her gastroduodenoscopy was normal. Serum IgA-tissue transglutaminase antibody was negative. Stool workup did not show any pus cells, RBC's, ova or cysts. Stool culture was negative. Urine examination did not reveal any active sediment 


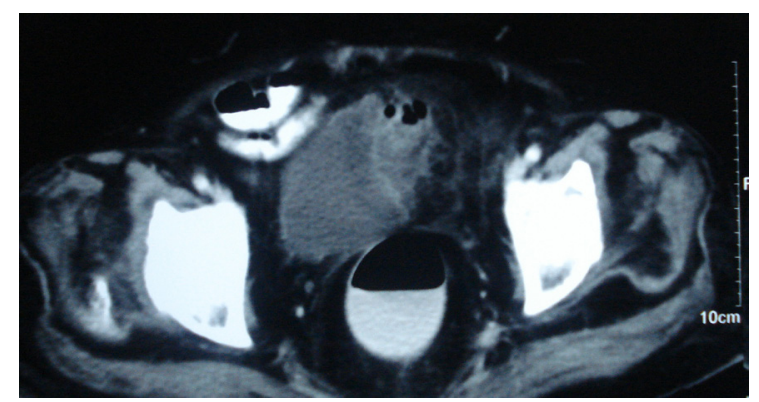

Figure 1. Asymmetrical mural thickening in the rectosigmoid.
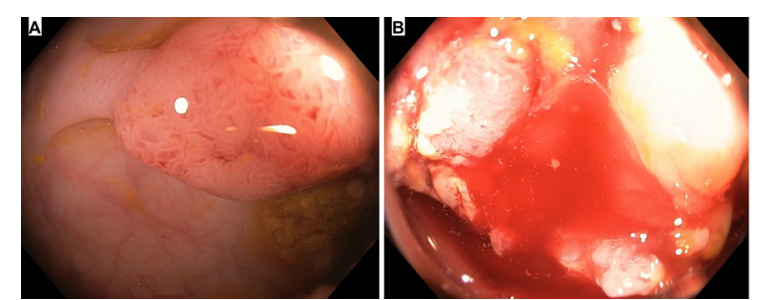

Figure 2. 2A Rectal polyp 2B Polypoidal malignant appearing lesion.

and the ultrasound for kidneys was normal. After her renal functions improved a contrast enhanced CT scan of abdomen and pelvis revealed asymmetrical mural thickening along with polypoidal growth involving rectosigmoid colon (Figure 1). Sigmoidoscopic examination revealed a small polyp at $15 \mathrm{~cm}$ and a large polypidal friable lesion at $18 \mathrm{~cm}$ from anal verge (Figure $2 \mathrm{~A}$ and $2 \mathrm{~B})$. Rest of the colonic mucosa was normal and free of polyps. Biopsy taken from the larger lesion was consistent with adenocarcinoma. Hypokalemia was corrected by oral and intravenous correction. The patient was referred to surgical services for further management.

\section{Discussion}

Rectal growth presenting as chronic diarrhea with hypokalemia is a rare cause of hypokalemia which was first described by McKittrick and Wheelock in 1954 (1). The disease classically presents as a triad of chronic diarrhea, dyselectrolynemia, and renal failure (2-7). We did an extensive PubMed search for all the cases of McKittrick and Wheelock syndrome reported in the English language up to March 2016. We used search terms "McKittrick", "AND" "Wheelock". Of the 44 results, four results were irrelevant and of the other 40 we excluded 9 because they were not in English language. The other 31 papers reported about 35 patients. We report the data on 35 cases of this syndrome in English literature (Table 1).

The mean age of presentation of these patients was $65.8 \pm 10.11$ years. The youngest age of presentation was a 30 years old male and the oldest case was an 82 years old female (8-9). There have been 17 female patients and 18 males reported indicating that the phenomenon is equally common in either gender. The
Table 1. Features of 35 cases of McKittrick-Wheelock syndrome reviewed

\begin{tabular}{ll}
\hline Feature & Result \\
\hline Mean Age (years) & $65.8 \pm 10.11$ \\
Gender (Male: Female) & $18: 17$ \\
Etiology & Villous adenoma - 21 \\
& Carcinoma - 7 \\
& Tubulovillous adenoma - 5 \\
& Heuroendocrine tumor -1 \\
& $22.9 \pm 33.9$ \\
Duration of symptoms (months) & Watery - 28 \\
Pattern of diarrhea & Bloody - 7 \\
Renal failure & 30 \\
Hypokalemia & Present - 26/27 \\
Hyonatremia & Data NA - 8 \\
& Present - 22/23 \\
Shock & Data NA - 12 \\
Outcome & 7 \\
\hline
\end{tabular}

mean duration of symptoms prior to presentation was $22.9 \pm 33.9$ months with a minimum and maximum interval prior to presentation ranged between one month and ten years ( 1 ).

Our patient had all the features of the classical triad. Although the diarrhea is classically watery in nature, seven cases out of all the 35 reported cases had associated blood in stools (10-14). This can be expected as rectal bleeding is an important clinical feature of rectal cancer and polyps. Of seven patients with bleeding, only two patients had underlying malignancy while five had rectal villous adenoma. Renal failure was found to be present in 30 out of 35 reported cases at presentation with 3 patients not having renal injury and data was not available for 2 patients (15-17). The mean blood urea nitrogen and creatinine values at presentation were $106.1 \pm 60 \mathrm{mg} / \mathrm{dL}$ and $5.1 \pm 2.96$ $\mathrm{mg} / \mathrm{dL}$ respectively. The maximum value of BUN and creatinine reported were 220 and 11.7 respectively (1819). Most of the patients achieved complete recovery with adequate hydration and surgical/endoscopic removal of lesions. Twenty nine cases achieved full recovery from renal failure, one patient did not undergo treatment and her outcome was not known (19). Our patient's renal failure also improved with hydration. Dyselectrolynemia is generally universal and was seen in all the patients. The mean values of potassium and sodium were $2.57 \pm 0.78 \mathrm{meq} / \mathrm{L}$ and $118 \pm 11 \mathrm{meq} / \mathrm{L}$ respectively. All the patients improved with medical and later surgical management. Most patients had chronic diarrhea and are fluid replete with increased compensatory fluid intake, however, a few cases presented with hypovolemic shock. Seven out these 
35 cases were in hypovolemic shock at presentation $(8,11,18-21)$.

The pathogenesis of diarrhea is due to the secretory activity of villous adenoma. Around 3\% of villous adenoma has secretory activity and it is proportional to its size (22). The reason why only rectal (distal colonic) lesions are implicated in hypokalemia is because the distal location of lesion prevents compensatory colonic absorption leading to diarrhea, which even persists with fasting. Rectal location was the most common seen in 30 cases. Four patients had a large adenoma extending into sigmoid colon $(7,16,23,24)$ and one patient had an extremely large adenoma extending from rectum into descending colon (11). The electrolyte depletion causes hypokalemia, hyponatremia, dehydration and metabolic acidosis. Our patient had severe hypokalemia at presentation which required a high dose of potassium correction daily. Prostaglandins (PGE2) has been postulated as a secretagogue responsible for this diarrhea (25). A study demonstrated markedly increased levels in diarrheal fluid (26). In a recently reported case, strong COX-2 expression was shown in goblet glands using immunohistochemical staining (23).

Majority of reported cases are due to a villous adenoma, however, rarely it can be secondary to an adenocarcinoma or even a neuroendocrine tumor (7). Out of 35 cases, 22 had a villous adenoma, eight cases had an underlying adenocarcinoma $(8,11,14,21$ 22,27-29) one each had a hyperplastic polyp (30) and neuroendocrine tumor of rectum with liver metastasis (7). Histological details were not available for 3 cases (15). Management includes correction of dehydration and electrolyte abnormalities followed by a definitive therapy for removal of polyp. Medical therapy with indomethacin and somatostatin have been tried to reduce secretion from polyps (25). Endoscopic and surgical methods of polyp removal can be used. Our patient had an underlying adenocarcinoma which has so far been reported only in eight cases. Out of the 36 cases, one patient refused all treatment modalities (19); only one was managed with an endoscopic method using endoscopic submucosal dissection (29). Two patients refused surgery and were managed with medical therapy alone $(7,15)$. The other 32 patients underwent surgery. Seven patients underwent laparoscopic anterior resection and the rest were managed with open surgery. It is likely that in the future many patients will be managed without surgery due to advancements in the field of endoscopic resection with use of endoscopic mucosal resection and endoscopic submucosal dissection.

Some of the patients suffer from underlying comorbidities and complications making management difficult. The various comorbidities reported so far are Cronkhite Canada syndrome (22), thalassemia (8), hypothyroidism (16), cirrhosis (9), deep vein thrombosis (31), diabetes mellitus (29), dermatomyositis (13) and even monoclonal gammopathy of undetermined significance (24). The role of the above comorbidities in being the causative factor or just chance association is unclear. The reported complications in the literature included associated endocarditis (19), pseudoobstruction (32), rhabdomyolysis (20), clostridium difficle induced diarrhea (33), intussception and rectal prolapse (12). Postoperative complications such as postoperative stricture (29) have been reported which require multiple sessions of rectal dilatations.

To conclude, McKittrick and Wheelock syndrome although uncommon, is an important differential diagnosis in patients presenting with electrolyte abnormalities, renal failure and secretory diarrhea. If promptly diagnosed and treated, it is a reversible illness. Definitive treatment requires excision of adenoma after correction of electrolyte abnormalities which can be lifesaving.

\section{References}

1. McKittrick LS, Wheelock FC Jr. Carcinoma of the colon. Charles C Thomas Springfield, IL, 1954; pp.61-63.

2. Nicholson P, Naugler C. McKittrick-Wheelock syndrome may represent the extreme of a normally distributed continuum of secretory activity in colorectal villous adenomas. Clin Chim Acta. 2014; 436:9-10.

3. Kapoor S. Mckittrick-Wheelock syndrome: An often, overlooked complication of rectal adenomas. Surg Endosc. 2014; 28:2247.

4. Bozkurt N, Omer Özütemiz A, Akgün E, Doganavsargil B, Sezak M. Adenoma with rectal villous diarrhoea and severe hypokalaemia (McKittrick-Wheelock syndrome). Br J Hosp Med (Lond). 2013; 74:648-649.

5. Fernández-López F, Paredes-Cotore JP. McKittrickWheelock syndrome- Prolapsed giant villous adenoma of the rectum. Rev Esp Enferm Dig. 2013; 105:309-310.

6. Winstanley V, Little MA, Wadsworth C, Cohen P, Martin NM. The McKittrick-Wheelock syndrome: A case of acute renal failure due to neoplastic cholera. Ren Fail. 2008; 30:469-473.

7. Nakhla SG, Murakami TT, Sundararajan S. Poorly differentiated neuroendocrine tumor of the rectum coexistent with giant rectal villous adenoma presenting as McKittrick-Wheelock syndrome. Case Rep Oncol Med. 2015; 2015:242760.

8. Lee YS, Lin HJ, Chen KT. McKittrick-Wheelock syndrome: A rare cause of life-threatening electrolyte disturbances and volume depletion. J Emerg Med. 2012; 43:e171-e173.

9. Podestà MA, Cucchiari D, Merizzoli E, Elmore U, Angelini C, Badalamenti S. McKittrick-Wheelock syndrome: A rare cause of acute renal failure and hypokalemia not to be overlooked. Ren Fail. 2014; 36:811-813.

10. Sanchez Garcia S, Villarejo Campos P, Manzanares Campillo Mdel C, Gil Rendo A, Muñoz Atienza V, García Santos EP, Ruescas García FJ, Bertelli Puche JL. Hypersecretory villous adenoma as the primary cause of an intestinal intussusception and McKittrick-Wheelock syndrome. Can J Gastroenterol. 2013; 27:621-622.

11. Choi WH, Ryuk J, Kim HJ, Park SY, Park JS, Kim JG, Choi GS. A case of giant rectal villous tumor with severe 
fluid-electrolyte imbalance treated by laparoscopic low anterior resection. J Korean Surg Soc. 2012; 82:325-329.

12. Galanis IN, Dragoumis DM, Christopoulos PN, Galanis NN, Atmatzidis KS. Giant villous adenoma and McKittrick-Wheelock syndrome in an incarcerated rectal prolapse. Colorectal Dis. 2010; 12:382-384.

13. Koning GG, Rensma PL, van Milligen de Wit AW, van Laarhoven CJ. In-one-continuity rectal excision and anal mucosectomy of a giant villous adenoma: An alternative surgical approach. Case Rep Gastroenterol. 2008; 2:175180.

14. Lepur D, Klinar I, Mise B, Himbele J, Vranjican Z, Barsić B. McKittrick-Wheelock syndrome: A rare cause of diarrhoea. Eur J Gastroenterol Hepatol. 2006; 18:557559.

15. Dagan A, Reissman P. Giant secretory villous adenoma of the rectum and sigmoid presenting as McKittrickWheelock syndrome. Int J Colorectal Dis. 2010; 25:909910.

16. Caliskan C, Makay O, Firat O, Uğuz A, Akgün E, Korkut MA. McKittrick-Wheelock syndrome: Is it really rare? Am J Emerg Med. 2010; 28:105-106.

17. Targarona EM, Hernandez PM, Balague C, Martinez C, Hernández J, Pulido D, Berindoague R, Trias M. McKittrick-Wheelock syndrome treated by laparoscopy: Report of 3 cases. Surg Laparosc Endosc Percutan Tech. 2008; 18:536-538.

18. Martins HS, Brandão-Neto RA, de Carvalho AL, Santana AN, Aguiar FJ, Scalabrini-Neto A, Velasco IT. McKittrick-Wheelock syndrome: A cause of severe hydro-electrolyte disorders in ED. Am J Emerg Med. 2007; 25:1083.e1-e3.

19. Dahya V, Dahya Z, Cua Y. McKittrick-Wheelock syndrome complicated by Enterococcus faecalis endocarditis: A unique combination. Int J Colorectal Dis. 2015; 30:285-286.

20. Pucci G, Rondelli F, Avenia N, Schillaci G. Acute renal failure and metabolic alkalosis in a patient with colorectal villous adenoma (McKittrick-Wheelock syndrome). Surgery. 2013; 154:643-644.

21. Tuţă LA, Boşoteanu M, Deacu M, Dumitru E. McKittrick-Wheelock syndrome: A rare etiology of acute renal failure associated to well-differentiated adenocarcinoma (G1) arising within a villous adenoma. Rom J Morphol Embryol. 2011; 52:1153-1156.

22. Watari J, Sakurai J, Morita T, et al. A case of Cronkhite-
Canada syndrome complicated by McKittrickWheelock syndrome associated with advanced villous adenocarcinoma. Gastrointest Endosc. 2011; 73:624-626.

23. Hsieh MC, Chen CJ, Huang WS. McKittrick-Wheelock syndrome. Clin Gastroenterol Hepatol. 2016; 14:e41-e42.

24. Hashash JG, Holder-Murray J, Aoun E, Yadav D. The McKittrick-Wheelock syndrome: A rare cause of chronic diarrhoea. BMJ Case Rep. 2013; 2013. pii: bcr2013009208.

25. Smelt AH, Meinders AE, Hoekman K, Noort WA, Keirse MJ. Secretory diarrhea in villous adenoma of rectum: Effect of treatment with somatostatin and indomethacin. Prostaglandins. 1992; 43:567-572.

26. Popescu A, Orban-Schiopu AM, Becheanu G, Diculescu M. McKittrick-Wheelock syndrome - a rare cause of acute renal failure. Rom J Gastroenterol. 2005; 14:63-66.

27. Bruno A, Chimienti D, Montanaro A, Prete F, Libutti P, Lisi P, Basile C. The Mckittrick-Wheelock syndrome: A rare cause of severe hydroelectrolyte disorders and acute renal failure. Case Rep Nephrol. 2011; 2011:765689.

28. Raphael MJ, McDonald CM, Detsky AS. McKittrickWheelock syndrome. CMAJ. 2015; 187:676-678.

29. Ohara Y, Toyonaga T, Watanabe D, Hoshi N, Adachi S, Yoshizaki T, Kawara F, Tanaka S, Ishida T, Okuno T, Ikehara N, Morita Y, Umegaki E, Yokozaki H, Azuma T. Electrolyte depletion syndrome (McKittrickWheelock syndrome) successfully treated by endoscopic submucosal dissection. Clin J Gastroenterol. 2015; 8:280284.

30. Vercauteren C, Van de Putte, Pattyn P. McKittrickWheelock syndrome: Acute renal failure by a colorectal adenoma. A case study. Acta Chir Belg. 2012; 112:226228.

31. Khalife M, Eloubeidi MA, Hosn MA. McKittrickWheelock syndrome presenting with dermatomyositis and rectal prolapsed. Clin Exp Gastroenterol. 2013; 6:85-89.

32. Miles LF, Wakeman CJ, Farmer KC. Giant villous adenoma presenting as McKittrick-Wheelock syndrome and pseudo-obstruction. Med J Aust. 2010; 192:225-227.

33. Learney RM, Ziprin P, Swift PA, Faiz OD. Acute renal failure in association with community-acquired clostridium difficile Infection and McKittrick-Wheelock syndrome. Case Rep Gastroenterol. 2011; 5:438-444.

(Received February 26, 2016; Revised May 9, 2016; Accepted May 10, 2016) 